\title{
A Novel Faculty-WIDE APProach to Teaching SECOND Year Engineering Design and Professional Practice
}

\author{
David S. Strong and Brian Frank \\ Queen's University, Kingston, Ontario, Canada \\ strongd@queensu.ca
}

\begin{abstract}
In the 2011-2012 academic year Queen's University introduced a new second year faculty-wide design course as part of its initiative to create a four year Engineering Design and Practice Sequence (EDPS) in all engineering programs. This paper discusses the structure, delivery, results, and feedback on the first offering of the second year EPDS course. Based on learning objectives developed by a faculty-wide curriculum committee, the one-term course was designed with a novel hybrid delivery process. The structure incorporates common instructional material and integrated projects across all departments during the first half of the course, and continues with discipline-oriented projects to enhance and reinforce the overall learning objectives through the latter half. Over 600 second year students from the Faculty of Engineering and Applied Science were enrolled, and more than a dozen instructors and 34 teaching assistants were involved in the course delivery over both academic terms. Details of the course structure, examples of instructional material and projects, and feedback from all representative parties are discussed.
\end{abstract}

Keywords: design, professional skills, design sequence, professional spine, graduate attributes.

\section{INTRODUCTION}

In June 2009, the Faculty of Engineering and Applied Science at Queen's University undertook a strategic curriculum review process designed to enrich undergraduate engineering education while meeting or exceeding the new CEAB graduate attributes accreditation requirements. One of the key initiatives from this effort was a commitment to develop a four-year Engineering Design and Practice Sequence (EDPS) of project-based courses. This four-year sequence has been adopted as a core requirement for all engineering students, and will develop competence in professional attributes including design process methods and tools, problem analysis, creativity, economics and entrepreneurship, engineering communications, professionalism, and ethics.
Prior to 2011, Queen's engineering had practiced a typical "bookend approach" to engineering design. Most students were exposed to a relatively non-technical design project in first year and a very technical capstone design project in their fourth and final year, with little design experience in second and third years. This approach has been demonstrated to lead to poor design skill retention, and, in fact, regression in both confidence and ability to apply a design process [1] [2]. Professional skill development in many programs was also limited largely to the first and fourth years.

The development of a four-year Engineering Design and Practice Sequence (EDPS) of project-based courses at Queen's is directed by a Curriculum Review Committee (CRC) consisting of representatives from all engineering programs in the faculty of engineering, a student society representative, the Associate Dean, the Director of Program Development, the NSERC Chair in Design Engineering, and members with economics, library, and professionalism expertise.

Our curriculum design draws upon the cognitive apprenticeship framework from Collins, Brown, and Newman that builds upon the idea of an apprenticeship which "embeds the learning of skills and knowledge in their social and functional context" [3]. Recent engineering reports have recommended curricular changes based on these approaches, including a spine of courses that emulates professional practice [4]. A spiral curricular model was adopted, in which common concepts and objectives are developed in all four years, with greater scaffolding in early years, and increasing complexity over time [5]. More detail about the EDPS, including objectives and delivery, is presented in [6].

The course making up the first year of the sequence, EDPS I, is a three module project-based course known as APSC-100 focusing on complex problem solving, design of investigations, and team-based client projects. The course develops skills in design process, problem solving, information literacy, teaming, communications, ethics, investigation, use of engineering tools, economics and project management, and professionalism. These objectives are further developed in the second year of the sequence, EDPS II, which is the focus of this paper. 


\section{COURSE DESCRIPTION}

\subsection{Learning Outcomes and Structure}

The learning outcome for EDPS II evolved over several years by a faculty wide curriculum committee. These outcomes were built around the concept of a four year sequence of EDPS courses, and therefore the outcomes targeted for this course were designed for the second year in the course series. The specific learning outcomes are:

- Demonstrate enthusiasm for engineering and the discipline they have selected

- Apply design processes and tools for problem definition, idea generation and decision making

- Promote creative processes in open ended problem solving

- Apply engineering principles and theories from other disciplinary courses

- Solve an open-ended design problem (involving analysis and/or simulation and/or prototyping)

- Analyze triple bottom line (financial, environmental, and public interest) to support decision making

- Apply relevant engineering regulations/codes/standards in a professional manner

- Explain the role of professional/technical associations in engineering and discipline

- Apply teaming skills in a group project

- Identify all relevant factors and the dominant factors in the system

- Apply information search and identification, with proper citations

- Demonstrate a communications strategy that considers the needs and character of the audience

- Compose logical arguments based on supporting evidence

- Compose with the appropriate structure and relationship amongst ideas

- Prepare and deliver a presentation with appropriate language, style, timing and flow

- Demonstrate writing with correct spelling, punctuation and grammar

- Demonstrate conciseness, crispness, precision and clarity of language

- Use appropriate formatting for a memo and a short report

To address these outcomes, EDPS II was structured to be project-based with integrated instruction material, designed to be delivered in three parts over a 12-week semester. The three segments of the course are referred to as $\mathrm{P} 0, \mathrm{P} 1$, and $\mathrm{P} 2$. $\mathrm{P} 0$, or project zero, engages students in a challenging yet fun project with "zero" instruction, other than that received in their first year program. P1 is intended to develop design, professional practice, and communications competence through just-in-time instruction concurrent with an integrated non-discipline specific project. The third section of the course, $\mathrm{P} 2$, is intended to reinforce and supplement the learning from P0 and P1 in the context of a discipline oriented project.

EDPS II was split into two integrated courses for the purpose of grading to allow communication skills to be broken out and reported in a separate course. APSC-293 is focused exclusively on engineering communications, while APSC-200 focuses on everything else. Deliverables are common to both courses; grading related to communications is simply reported in APSC-293. The two courses were delivered by the same team of instructors and teaching assistants (TA's) and were completely integrated except for the purpose of grading.

EDPS II was first offered to $\sim 310$ students in Electrical, Computer, Civil, Geological, and Mining Engineering, Engineering Physics and Engineering Math in Fall 2011, then to the remaining 315 second year students in Mechanical and Chemical Engineering, and Engineering Chemistry in Winter 2012.

The first half-term segment (including P0 and P1) was delivered to two separate lecture sections, each with $\sim 165$ students, 8 TAs (comprised of an approximately equal mix of final year undergraduate and graduate students) and a course instructor. Each week typically incorporated two lectures and two, two-hour workshops, the latter given in smaller sub-sections of about 45-60 students. Each TA was typically responsible for 5 student teams (about 20 students) and followed those teams through the entire course.

Course curricula were developed to meet the outcomes set forth by the curriculum committee. Although generally planned in advance of the course, many elements were modified during the first term based on real-time feedback from the students and TA's, to optimize the results. The general course structure is graphically described in Figure 1 for clarity.

2.1.1 Week 1: P0 Project. The first week of the course, "P0", was designed to provide a teambuilding opportunity as well as a short design project upon which the students could reflect over the remainder of the course. Departments were given the opportunity to choose whether to develop and run the P0 segment for their own students or alternately to have them involved in a "Faculty" developed offering. Two thirds of the students participated in the Faculty version, and the remainder engaged in departmentally run P0 activities. Only the Faculty version is described for brevity.

In the faculty-developed P0 students worked for a week in groups to complete a simple design-build-test task using recycled/reused materials. The intent was to encourage creativity and team-building, given minimal structure or design instruction, and also to stimulate interest in the design process and encourage students to 


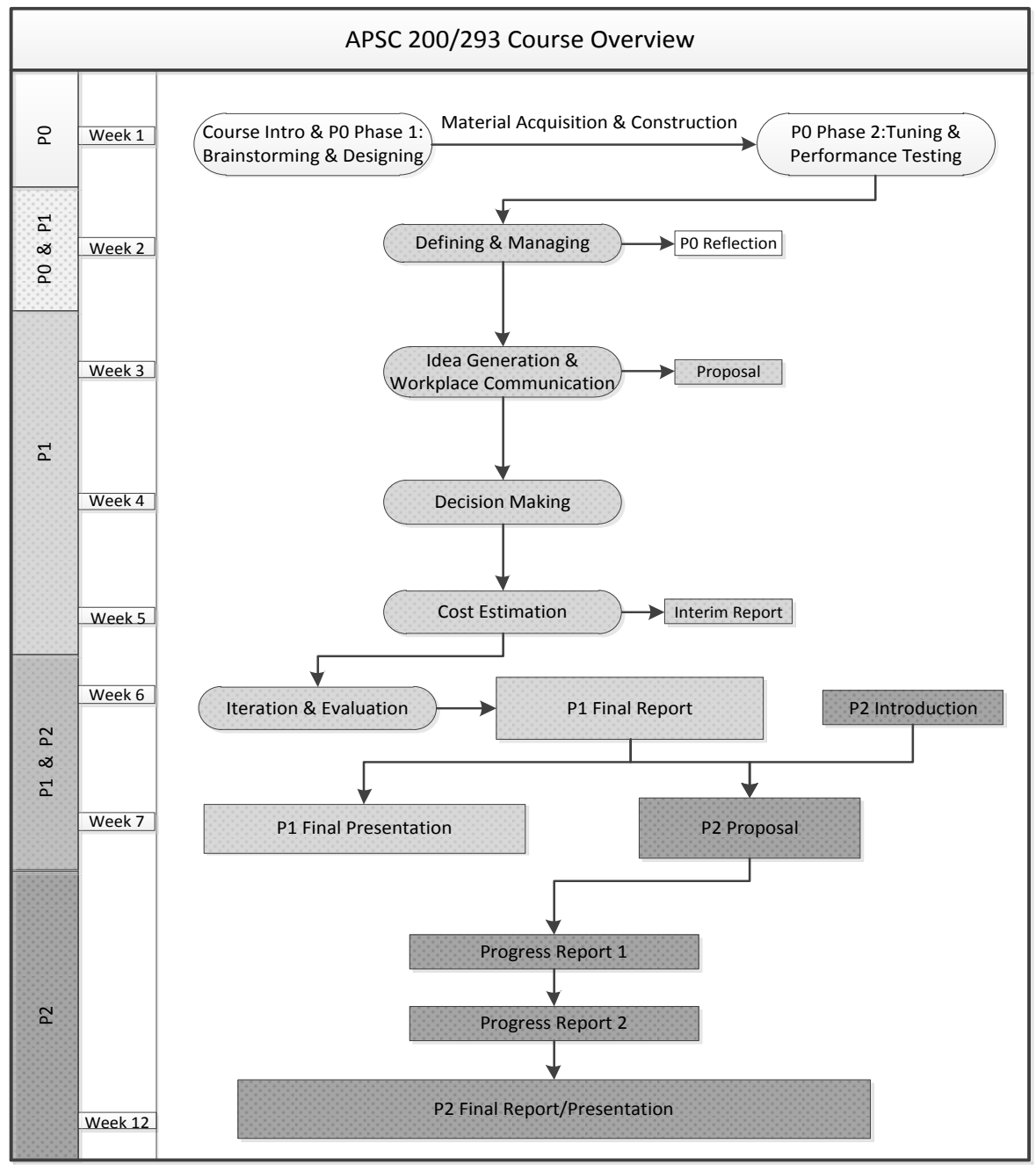

Figure 1 - Simplified structure of APSC 200/293

enjoy and reflect on the experience. The task was to design a device for propelling a "package" towards a target, and build said device using discarded or repurposed materials wherever possible. Although presented in the context of a "rescue mission", the challenge was essentially to build a device to propel practice golf balls through a choice of targets. The testing was run in the form of a competition by class section to encourage the excitement and engagement,

The P0 exercise was structured in two Phases, one in each workshop session, as follows:

Phase 1 - Conceive and Design: During an introductory lecture outlining the course objectives and structure, students were given the $\mathrm{P} 0$ problem description as well as the link to find their pre-assigned teams. In the first 2-hour workshop, the teams were given the task of generating one or more conceptual designs to solve the challenge, prior to departing the session. The instructor and TA's circulated to encourage the students, but no definitive design process instructions were provided. Student questions were typically referred back to the written description of the project in order to encourage students to make their own decisions. At the end of the workshop each teams submitted design description and concept sketch(s) and a proposed materials list for their TA to review. No grades were given for this exercise; it was simply a sign-off to ensure the students were engaged in the activity. For "homework", students were encouraged to seek out materials and build their designs on their own time to ensure they were ready for the next phase.

Phase 2 - Implement and Operate: The first hour of the second workshop was utilized to allow the students to refine their designs. Each team was allotted two, two minute practice times using the targets to test and adjust their devices for optimum performance. The second hour was allocated to the final testing of each team's device. In every case these sessions were energetic and fun, and while there was a degree of competition between teams, there was tremendous support for others. All of the teams were graded on their accomplishments, with $80 \%$ of the 
grade towards the design and construction of the device, and $20 \%$ for performance.

Following this session, all students were asked to write and submit an individual reflective review on the P0 project. Several general questions were provided to the students to foster reflective thinking on process, communication, and time management, but students were encouraged to supplement their responses with their own thoughts or comments. This exercise served to provide a comparative design and teamwork experience for entering the instructional portion of the course, as well as to establish a baseline for each student's written communication capability.

\subsubsection{Weeks 2-6: P1 Project and Supporting Instruction/Activities. Common instruction material} and activities were provided to all students in the P1 segment in weeks 2-6, as concurrently as possible with project requirements. Instruction topics covered in this segment included design process and tools, written and verbal communication, formal and informal presentations, design economics, codes and standards, safety, ethics, and societal/environmental considerations. Communication elements such as engineering reports, presentations, and workplace interactions were interwoven with the design instruction within the context of the workshops and project activities.

In parallel with the instruction, student teams were assigned a design project chosen to encourage the application of curricular material. The theme for the projects for this first year was "Humanitarian Engineering". The project was intended to be "virtual", although students were not discouraged from building all or part of a prototype. Student teams were asked to design a device sized appropriately for a family or small village from amongst three different project topics. In parallel they were required to research and choose a country/region of implementation for application context. Three different topics were offered in each term of the course. As an example, the fall term choices were:

- Energy Generation and Storage

- Water supply and Purification

- Sustainable energy cooking

Modular lectures and active workshop exercises were delivered to coincide with the stages of the design project. APSC 200 design instruction elements included overall design process, problem definition and scoping, information research, idea generation and creativity techniques, project management, safety, decision making tools (pros/cons table, weighted evaluation matrix), value judgment (triple bottom line), cost estimation, design assessment and iteration. Project deliverables were a design proposal, interim and final reports, and an oral presentation.

APSC 293 communication workshops begin with a general lecture outlining the engineering writing process, then throughout the project on a just-in-time basis the topics supported the various reporting aspects, including business communications and information research. Students were also asked to make brief individual verbal summaries on behalf of their team during many of the active workshops. These were rotated through the team members to ensure that every student had multiple opportunities to speak to the class.

2.1.3 Weeks 7-11: The P2 project. The P2 course segment centered on a discipline-oriented design project delivered by each department, with the objective of enhancing the same overall course learning outcomes targeted in $\mathrm{P} 0$ and $\mathrm{P} 1$. The communication content includes a small number of integrated lectures, online modules, and working tutorials practicing communication in the engineering context of deliverables in the design course.

Retaining the same timetabling as the first half of the course, the P2 segment was led by departmental instructors working with the same TA's and students in the same teams as in P0 and P1. The departmental instructors determined if and how the lecture and workshop slots would be used based on the needs of their particular project assignment. Typically one lecture and one workshop per week retained scheduled activities and the second workshop was offered as unstructured project time, although there was substantial variation.

Students tackled a discipline related design project proposed by their department and reviewed by the Curriculum Review Committee, to effectively illustrate the application of the design principles outlined in the first 6 weeks in a disciplinary context. No formal instruction was planned for this portion of the course, although some departments provided supporting technical instruction relevant to the project. Students were expected to follow the design, project management, and communication processes learned in the P1 segment. Although the course co-ordinator oversaw this final project, the departmental instructors were responsible for the specific content and structure.

Projects offered in the P2 phase varied in technical complexity, in part depending on the term offered. Students taking the course in the second term had a slightly higher level of technical capability from their first term experience. However, several of the first term departmental instructors compensated to some degree with supporting lectures to compliment the projects.

Example design project topics included: a cell phone charger using recreational activities for energy supply; an improved mine ventilation system; and response to a chemical spill. The latter was a great example of integrating design process, professional practice, and communication. The project challenge was to manage and remediate a spill of 1000 litres of trichloroethylene on a busy street in the heart of the university campus. 
Student teams designed solutions to remediate the spill while also managing pedestrian and road traffic and ensuring safety of bystanders and cleanup workers. This required understanding of all relevant laws and standards, communication with external bodies such as the city's emergency response personnel and provincial oversight organizations such as Ministry of the Environment, learning and implementing safe practices required for the site, as well as the technical requirements to capture, remove, and remediate the contaminated material.

\subsection{Assessment}

Given the integrated nature of the courses, student assessment incorporated a combination of technical, process, and communication elements. Student deliverables were designed accordingly. For example, the P0 project (week 1) assessed the design proposal, the simplicity, reliability, efficiency and reproducibility of their prototype, the use of recycled/reused materials, and the final accuracy of their device in hitting the target. An individual written reflective submission, guided by several suggested questions, was also submitted and assessed for communication skills.

Deliverables for both the P1 and P2 projects consisted mainly of a series of project reports (preliminary/proposal, interim/progress, and final). In order to emphasize the importance of communication in engineering practice, wherever possible, course deliverables were marked and given formative feedback on both design and communication content. With the combination of open-ended projects, multiple levels of reports, and the dual nature of the assessment, students were provided with a rubric for content and clarity that could be used for all levels of reporting, combined with guidelines for each specific deliverable. Significant oversight was required to maintain consistency across the many TAs and sections. TAs participated in training and discussion prior to assessment as well as follow-up discussion and cross-assessment for calibration and adjustment.

Rubric development for design project reporting is a challenging task; however, prior experience led us to apply Fostaty Young \& Wilson's “Ideas, Connections, Extensions" approach to assessment and learning [7]. This methodology incorporates three categories of learning achievement: the first is ideas, typically in the form of knowledge or information; the second, connections, demonstrates relationships between knowledge, fundamental skills, and/or previous knowledge; the third, extensions, involves the application of the new learning in novel ways, often with creative, critical, and/or reflective insight. General descriptions of these learning achievements, suitable for a second year program, were created for both content and communication, and provided to the students and the instruction/assessment team. This rubric was then applied in conjunction with the individual deliverable guidelines to provide feedback and grade. Once the TA's were familiarized with this methodology and had some experience applying it, post-assessment calibration indicated that the grading was remarkably consistent, requiring only one sub-section deliverable adjustment over two terms with dozens of deliverables.

Detailed peer reviews were required at the end of each of the two main projects. Students were instructed to divide "marks" amongst their team in two categories generally classed as knowledge/capability and teamwork/effort, along with free-form comments to reinforce their numerical reviews. Students were informed in advance that this could adjust their mark in each of the two project phases by adding up to $3 \%$ bonus or deducting up to a $25 \%$ penalty. This, along with the individual reflection deliverables and participation/engagement grading, allowed significant variation in marks within teams, where appropriate.

As with EDPS I, grading for deliverables was done in the university's on-line learning management system, Moodle, using a similar modular input process. The overall average grade for the full second-year student body was a B. A total of 6 students received failing grades, all as a combined result of poor individual submissions and significant negative mark adjustments due to minimal team contributions noted clearly in the peer review results and comments. While never desirable to give failing grades to students, particularly in a course where any engineering student should be able to pass, it does confirm the efficacy of the individual deliverables and peer review adjustments in preventing nonparticipative students from passing simply due to being part of an otherwise successful team.

\section{FEEDBACK AND CHALLENGES}

\subsection{Student Feedback}

Student feedback is essential, especially given the size, complexity, and first implementation of EDPS II, with multiple instructors, TA's, sections, and projects producing variation in the student experience, despite substantial efforts to keep the focus of the course on the common learning objectives. A post-course student survey was designed with this in mind, and students were asked to review the learning objectives prior to beginning the survey. These objectives had been presented to the students in the first lecture and discussed on several occasions throughout the course.

The survey incorporated 35 questions with 5-point Likert scale response options, and an invitation to include free-form comments. The first 20 questions of the survey were relevant to the overall course, such as how well it met the learning objectives, how many hours per week the 
students invested, and other topics regarding the organization and perceived value of the course. The remainder of the survey focused on each of the projects, P0, P1, and P2, their individual value and how well they were linked. Although the instruction during the first half of the course was in multidisciplinary sections, the workshops, P1, and P2 projects were structured departmentally (due to timetabling constraints), hence the survey data was evaluated both as a whole and by department.

In the first term, the response to the survey was relatively low. In the second term, the survey was highly encouraged as a course requirement (although without marks) and the response rate was much higher, leading to an overall response rate over both terms of 335 students, representing $54 \%$ of enrollment. The responses to the P0, P1, and P2 phases varied substantially by discipline. The data suggests that the departmental variances may correlate with the type and complexity of the $\mathrm{P} 2$ project and workload in other courses.

Some of the key survey questions are presented below with the cumulative "strongly agree" and "agree" response percentage. The "neither agree nor disagree" response for all of these questions was very similar, ranging from $16 \%$ to $23 \%$ :

- Overall, this course was effective at meeting the objectives above (with the explicit learning objectives listed above the questionnaire) $-74 \%$

- The first half of the course provided an understanding of design process and related techniques necessary to effectively carry out the P2 project $-56 \%$

- $\quad$ The course helped me develop my ability to work as a team member $-79 \%$

- The course strengthened my ability to solve openended engineering problems $-73 \%$

- The course improved my skills in written and oral communications $-62 \%$

- This course helped me develop the ability to plan projects effectively $-64 \%$

- The project in the first week (the P0 project) was an effective activity to encourage team-building $67 \%$

- The project in weeks 2-6 (the P1 project) was an effective activity to meet the objectives above (again referring to the learning objectives listed above the questionnaire) $-64 \%$

- The P2 project reinforced elements learned in the first half of the course in a discipline-focused context $-67 \%$

These responses suggest a good level of satisfaction from the students. The response on the question of selfobserved improvement in communication skills was somewhat lower than expected, and in fact is inconsistent with the observations of the instruction team. No doubt there is a perception amongst some students, exemplified by some of the general comments received, that a course of this nature is "not engineering". Yet many others commented that the course was very relevant and enjoyable. Attempts were made by the instruction team to reinforce the value of and need for design, professional practice, and communication skills in engineering practice, but clearly that message is not universally accepted.

Upon reviewing the general comments, there were several clear differences noted between the types of P2 project offered and the student response, particularly with respect to the learning objectives surrounding professional aspects such as society, environment, and ethics. With open-ended projects focused on real-world scenarios, students were (or could be with instructional encouragement) "pulled" into consideration of these societal/professional elements. For those projects that were highly structured around technical analysis with tightly constrained "acceptable" response, students were forced to "push" these elements into the project. Paraphrased, the student response in their reports and/or presentation was, typically "... if we were to do this in the real world, we would have to consider the societal and environmental impact...". Student teams in these scenarios struggled to achieve assessment expectations in these areas, and many expressed their concerns in the comments section, indicating their awareness that the project was not conducive to drawing out these professional learning outcomes.

\subsection{TA Feedback}

At the end of each term, the TA's were asked to participate in a review to offer their comments and suggestions on the course. They were also invited to submit written comments, anonymously if they preferred. While the feedback was not collected with a survey instrument and is therefore not statistically presented, there were several relatively common themes:

- Both the TA's and students would benefit from a more detailed outline of the schedule, activities, and deliverables at the beginning of the course

- The student workload was reasonable given the weighting of the course, but the students need to better appreciate the heavier weighting versus a "standard" course

- A "contract" with the students would be helpful in ensuring student understand the course and team requirements and expectations, the assessment and grading process, and the peer review and late submission impact

- Attendance should be taken in some or all lectures and workshops to ensure all students can effectively contribute to their teams (Students 
were told that attendance was mandatory but actual attendance varied widely across sections)

- TA hours were at or slightly above the contractual arrangements of 60 hours per term, but there was wide agreement that they (the TA's) were enhancing their own design and professional skills through their involvement

- The TA's would benefit from somewhat more training in assessing the open-ended deliverables typical of these courses. (More training of this nature was desired by the instruction team but was limited due to budgetary constraints on TA hours)

- Students' writing skills generally improved over the duration of the term

- The P2 schedule seemed tight and would benefit from an extra week or two

Amongst the many comments offered by the TA team, one of the most interesting and rewarding was the expressed wish that they had been able to take a course like this in their program. Their interest and support was further reinforced by the fact that all who plan to return to Queen's next academic year offered to TA this course again.

\subsection{Instructor Feedback}

Instructors were also invited to offer their feedback in a wrap up meeting at the end of each term. No formal survey tool was used, and feedback was wide and varied. Some departments prefer to have more control over the type and timing of course deliverables, but the need for a degree of commonality for consistency and efficiency of administration was generally accepted. Similarly, there was mixed opinion on Faculty control on the overall curricula. It was also generally agreed that more and earlier information prior to the start of the courses would have been helpful, although recognized that the developmental nature of a first time course offering limited the ability to achieve this goal.

Review of the P2 projects led to discussion of variations in the nature and breadth of project topic between departments. As noted in the student feedback, there was general recognition that some of the projects were more successful in drawing out the professional engineering outcomes than others. However, there was also a degree of persistence in some cases that there must be strong technical elements within the $\mathrm{P} 2$ project. Discussions on this topic will continue as the preparations progress for the coming year.

\subsection{Implementation Challenges}

The first offering of EPDS II involved a course coordinator, 10 instructors, 33 teaching assistants, a full time course administrator, and 625 students from 10 engineering disciplines. Given the size and complexity of the course, its delivery over both terms in 4 sections and 12 sub-sections, and the 3 project phases, it was recognized from the beginning that variations and occasional issues would be inevitable.

Several issues with the introduction of a faculty-wide course of this size, and with the combined facultydepartment delivery method, are already evident, as follows:

- Communication amongst an instruction team of this size is critical, but extremely difficult to achieve. Significant advance planning and individual cooperation and flexibility are essential. Full instructor attendance at meetings was rare, so quorum was used for decision making where necessary, with immediate communication of such decisions following the meeting.

- Timetabling is a tremendous challenge. Scheduling the preferred arrangement of lectures and labs for every section was unachievable in the first year, and significant effort is being invested to improve this in the future.

- Course/Instructor assessment using universitywide standard formats is a requirement at Queen's, but does not apply well to modular project based courses with multiple instructors and phases. The custom survey was used to provide appropriate feedback, but students become surveyweary with all the required feedback.

- Developing the P1 project with the objective of being suitable for reinforcing design process, professional practice, and communication skills, and while making that project of relevance and interest to students in 10 engineering disciplines is a daunting task. Although efforts were made to explain to students that the P1 project topic was only intended for practice and reinforcement of the elements learned in the lectures and workshops, achieving acceptance for what was perceived to be "outside my discipline" requires further effort.

- While the objective of the P2 project was to provide the students with an opportunity to practice the knowledge and skills learned in the first half of the course on a discipline oriented project that would excite their interests in their field of choice, in some departments significant new technical material was incorporated, which diluted or deflected the intended learning objectives. This was particularly the case where a prior course was removed to make space for EDPS II, and to compensate the prior course material was squeezed into the 6 week P2 project.

- Administrative time in assisting with the planning and operation of these courses was substantial. It 
virtually consumed one person full time over both terms (in addition to significant coordinator time), and in fact resulted in substantial extra hours outside of the normal work day in order to compensate for other admin duties.

\section{CONCLUSIONS \& RECOMMENDATIONS}

Notwithstanding a selection of anticipated first-year challenges such as scheduling issues, minor miscommunications, and occasional oversights in preparation, the first offering of EDPS II has been considered successful. Communication between instructors in this hybrid teaching approach is critical, as is ensuring students have sufficient time to work on the course projects over the semester.

The term-end student surveys suggest that the majority of students' recognize achievement of course learning objectives. The data suggests that the choice and style of $\mathrm{P} 2$ project is linked to success in meeting these objectives, and to general student satisfaction.

Further research to better understand the students' learning and retention of the targeted outcomes is required in order to effect appropriate improvements. Analysis of the data continues and student focus groups studies are being planned.

In future years the course development effort will focus on designing projects that meet all the diverse course learning objectives characteristic of an integrated course. Additionally, detailed assessment of learning outcomes will be incorporated to assess the quality of the learning environment, and contribute to continual quality improvement processes required for accreditation.

\section{Acknowledgements}

The foundation for the EDPS spine discussed in this paper was a result of cross-faculty collaboration by the Dean's Retreat Curriculum Review Committee within the Faculty of Engineering and Applied Science at Queen's University. The EPDS II course, which is the focal point for this paper, was delivered by a large team of dedicated instructors and teaching assistants. The authors would like to acknowledge extensive contributions of these groups over the development of the EDPS spine.

Partial sections of this paper have been drawn from reference 6, a paper discussing planning for the full four year EDPS sequence, submitted to the 2012 CDIO conference, Brisbane, Australia. The authors of this paper gratefully acknowledge their co-authors on that publication, Lynann Clapham and Richard Sellens. The authors of this paper take full responsibility for its content, including any errors or omissions.

Funding provided by the Natural Sciences and Engineering Council of Canada (NSERC) through the Chairs in Design Engineering Program, and from DuPont through the DuPont Chair in Engineering Education, is gratefully acknowledged.

\section{References}

[1] Frank, B. and Strong, D.S., "Development of a design skills assessment Tool," in Proc. of the 2010 Canadian Engineering Education Association (CEEA) Conf., Kingston, ON, 2010.

[2] Kotys-Schwartz, D. et al., "First year and capstone design projects: Is the bookend curriculum approach effective for skill gain?", in American Society of Engineering Education (ASEE) Annual Conf., Louisville, KY, 2010.

[3] Collins, A., Brown, J., and Newman, S., "Cognitive Apprenticeship: Teaching the Craft of Reading, Writing, and Mathematics, ch. 14 , in Knowing, Learning, and Instruction. Essays in Honor of Robert Glaser, s.1, Laurence Erlbaum Associates, 1989.

[4] Sheppard, S., Macatangay, K., Colby, A., and Sullivan, W., Educating Engineers: Designing for the Future of the Field, Jossey-Bass, 2008.

[5] Dixon, A.G., Clark, W.M., and DiBiasio, D., "A projectbased, spiral curriculum for introductory courses in chemical engineering:II. Implementation," in Chemical Engineering Education, vol. 34, no. 4, 2000.

[6] Frank, B., Strong, D.S., Sellens, R., and Clapham, L., "Progress with the professional spine: A four year engineering design and practice sequence", accepted for publication in proceedings of the Conceive Design Implement Operate (CDIO) Conference, Brisbane, Australia, June, 2012.

[7] Fostaty Young, S., and Wilson, R., Assessment and Learning - The ICE Approach, Portage and Main Press (2000), ISBN 1-894110-64-1. 